\title{
2020: MURBURN CONCEPT HERALDS A NEW ERA IN CELLULAR BIOENERGETICS
}

\author{
Daniel Andrew Gideon, Vivian David Jacob, and Kelath Murali Manoj* \\ The Science \& Ethics Foundation, Snehatheeram, Kulappully, Shoranur-2, Kerala, India
}

Cellular bioenergetics has been interpreted for several decades using the Keilin-Mitchell-Boyer (KMB) model of oxidative phosphorylation (OxPhos), and for understanding/managing of the pertinent mitochondrial pathophysiological states. Although decades of research had revealed many faulty chemico-physical aspects of KMB perspective, recent critical insights from our group's writings have sufficiently brought out the errors in the KMB model, rendering it obsolete/redundant. The murburn model proposed in lieu is a compelling alternative for explaining OxPhos because it reasons several facets of mitochondrial structurefunction correlations, reaction chemistry and thermodynamics. However, the mitochondrial research community appears to be recalcitrant, and continues to follow the erstwhile erroneous ideas and not take cognizance of the new insights. Hence, we deemed it opportune to make a clarion call for a jettisoning of the superseded terminologies (or keywords) and concepts routinely used by researchers in this field. First, we present a statistical perspective of the usage of these terms in the past and recent times, to support our claims and call. Then, we articulate simplified arguments why the key elements/terms of the KMB model like "electron-transfer/electron-transport/respiratory chain", "mitochondrial proton pumps", "mitochondrial membrane potential", "chemiosmosis", "proton motive force" and "rotary ATP synthase/synthesis" violate scientific/semantic logic. Finally, we conclude with summative statements projecting the importance of our claims and call. Biomed Rev 2019;30:89-98

Keywords: murburn concept, aerobic respiration, mitochondria, murzymes, electron transfer/transport chain, ETC complexes, proton motive force, chemiosmosis, rotary ATP synthase, mitochondrial membrane potential, mitochondrial proton pumps

Received 15 December 2019, revised 31 December 2019, accepted 31 December 2019

*Correspondence to: Dr Kelath Murali Manoj, Satyamjayatu: The Science \& Ethics Foundation, Snehatheeram, Kulappully, Shoranur-2 (PO), Kerala, India-679122. Email: murman@satyamjayatu.com 


\section{A HISTORICAL PERSPECTIVE ON CELLULAR BIOENERGETICS AND THE RECENT DEVELOPMENTS}

In eukaryotes, mitochondria house the machinery driving oxidative phosphorylation (mOxPhos). In prokaryotes, the plasma membrane lodges the proteins involved in ATP synthesis. The pioneering work of Edward "Bill" Slater (1) proposed that a high energy enzyme intermediate carries out the chemical coupling step, to integrate $\mathrm{NADH} \rightarrow \mathrm{O}_{2}$ electron transfer with the synthesis of ATP. The search for an enzyme phosphorylating intermediate failed. Peter Mitchell proposed the chemiosmotic explanation $(2,3)$ which moots that electron transfer from one major element of electron transport chain (ETC) to another is associated with trans-membrane proton translocation, and this 'proton pumping' sets up a proton motive force driving the synthesis of ATP from ADP and Pi. Several notable scientists such as Slater et al published their objections to the chemiosmotic model (4-7). However, the chemiosmosis proposal became popular and the opposing views were ignored. Paul Boyer's rotary ATP synthase hypothesis was subsequently proposed in support of Mitchell's chemiosmosis model, to explain for the function of Complex V $(8,9)$. John Walker further improved on the ATP synthase model (10-12). Mitchell, Boyer and Walker were awarded Nobel prizes and their proposals are considered sacrosanct in bioenergetics.

While some others had questioned the chemiosmotic explanation, a comprehensive refutation of the KMB model (including electron transport chain and rotary ATP synthesis) was not established by any of its critics. In 2017-2018, one of us critically dissected and pointed out several underlying flaws and inaccuracies of the KMB model of mOxPhos, most of which even undergraduate students of biochemistry could understand. Combined with the new structural insights available on mitochondrial membrane complexes and two decades insights gained from heme peroxidase (HPO) enzymology and microsomal xenobiotics' metabolism ( $\mathrm{mXM}$ ) mediated by cytochrome P450 (CYP), a murburn explanation was proposed for the mOxPhos system (13-15). In the year 2019, we were joined in our efforts by some collaborators and this helped us to provide more substantial calculations and experimental evidence. We consolidated our claim that KMB model was thermodynamically and chemico-kinetically non-viable (13-17). We also demonstrated that the murburn model of mOxPhos provided better structure-function correlations of mitochondrial (super)complexes and overall phenomenology.

In the wake of 2020, even though murburn concept should have gained more traction with the community, the scientific community has not taken cognizance of our insightful pub- lications. Till date, the mainstream workers in the field of mitochondrial biology and bioenergetics have never voluntarily questioned or critiqued the murburn model of mOxPhos. Therefore, to up the ante and elicit a response from the entrenched researchers, we provide a summary of the words that portray scientific/semantic inaccuracies in the erstwhile model and show how the prominent journals still publish research that endorse these inaccuracies, even after 2 years of our launching of corrective measures. Later, we present a brief recapitulation of concepts and arguments to support our claims and call for discontinuation of outdated terms.

\section{A LITERATURE SEARCH FOR THE CITATIONS OF SCIENTIFICALLY OUTDATED TERMS}

We searched for articles (original research papers, reviews, commentaries and communications) in which the following keywords feature: "electron transfer/transport chain", "mitochondrial membrane potential", "chemiosmosis/chemiosmotic", "proton motive force", "mitochondrial proton pumps" and "rotary ATP synthase/synthesis". These terms are cited by a humongous number of research articles (reviews and research papers) only because many scientists assume the KMB model to be solid and uncontested, both of which are not factual. We start off with an overview of the keywords under discussion. The common and freely available internet search engines PubMed and Google Scholar were employed to find content containing the above groups of keywords. The returns were sought for the past fifty years (from 1968 until before the murburn hypothesis was published, i.e., 2018, which we term as "pre-murburn") and in 2019 alone (post-murburn era, i.e., from 2019 onwards). First, we searched within some journals with a heritage of publishing papers in bioenergetics and mitochondrial metabolism and the data are presented in Tables 1-2. To our surprise, we found that PubMed returned far fewer papers than Google Scholar. Also, the number given by Google Scholar was also a fraction of the hits obtained when the words were searched in the respective journals' websites. For example- Contrasting the 0 and 3 returns for 'ETC, electron transport/transfer chain' in Google scholar for the periods of 2019 and 1968-2018 respectively (as marked with an asterisk in Table 3), the official journal website of PNAS returned 212 and 3386 papers, within the same corresponding time-frame. For our immediate convenience and to keep matters less complicated, we searched for the publication frequency of the outdated terms in some ivy-league journals and all indexed journals using Google Scholar only, and these numbers are given in Tables 3 and 4 respectively. 
Table 1. Number of hits obtained using PubMed to search leading specialized journals in the field of mitochondrial biology and bioenergetics.

\begin{tabular}{|c|c|c|c|c|c|}
\hline $\begin{array}{c}\text { Term/ } \\
\text { Keywords }\end{array}$ & Period & $\begin{array}{l}\text { BBA-Bioenergetics } \\
\text { (Elsevier, since 1947) }\end{array}$ & $\begin{array}{l}\text { J. Bioenerg. Biomemb. } \\
\text { (Springer, since 1976) }\end{array}$ & $\begin{array}{c}\text { Mitochondrion } \\
\text { (Elsevier, since 2001) }\end{array}$ & $\begin{array}{l}\text { Front. Physiol. } \\
\text { Mitochondrial Research } \\
\text { (Frontiers, since 2010) }\end{array}$ \\
\hline \multirow{2}{*}{$\begin{array}{c}\text { Electron } \\
\text { Transfer/ } \\
\text { Transport Chain } \\
\text { (ETC) }\end{array}$} & 2019 & 1 & 0 & 9 & 5 \\
\hline & 1968-2018 & 4 & 160 & 124 & 18 \\
\hline \multirow{2}{*}{$\begin{array}{l}\text { Chemiosmosis/ } \\
\text { Chemiosmotic }\end{array}$} & 2019 & 0 & 0 & 0 & 0 \\
\hline & 1968-2018 & 48 & 17 & 0 & 0 \\
\hline \multirow{2}{*}{$\begin{array}{c}\text { Proton } \\
\text { motive force / } \\
\text { Mitochondrial } \\
\text { proton pump }\end{array}$} & 2019 & 4 & 0 & 2 & 0 \\
\hline & 1968-2018 & 7 & 95 & 48 & 0 \\
\hline \multirow{2}{*}{$\begin{array}{l}\text { Mitochondrial } \\
\text { membrane } \\
\text { potential }\end{array}$} & 2019 & 6 & 3 & 13 & 12 \\
\hline & 1968-2018 & 12 & 195 & 110 & 33 \\
\hline \multirow{2}{*}{$\begin{array}{l}\text { Rotary ATP } \\
\text { synthase/ } \\
\text { synthesis }\end{array}$} & 2019 & 0 & 1 & 0 & 0 \\
\hline & 1968-2018 & 0 & 9 & 0 & 1 \\
\hline
\end{tabular}

Table 2. Number of hits obtained using Google Scholar to search leading specialized journals in the field of mitochondrial biology and bioenergetics.

\begin{tabular}{|c|c|c|c|c|c|}
\hline $\begin{array}{c}\text { Term/ } \\
\text { Keywords }\end{array}$ & Period & $\begin{array}{l}\text { BBA-Bioenergetics } \\
\text { (Elsevier, since 1947) }\end{array}$ & $\begin{array}{l}\text { J. Bioenerg. Biomemb. } \\
\text { (Springer, since 1976) }\end{array}$ & $\begin{array}{c}\text { Mitochondrion } \\
\text { (Elsevier, since 2001) }\end{array}$ & $\begin{array}{l}\text { Front. Physiol. } \\
\text { Mitochondrial Research } \\
\text { (Frontiers, since 2010) }\end{array}$ \\
\hline \multirow{2}{*}{$\begin{array}{c}\text { Electron } \\
\text { Transfer/ } \\
\text { Transport Chain } \\
\text { (ETC) }\end{array}$} & 2019 & 61 & 9 & 47 & 58 \\
\hline & 1968-2018 & 3430 & 551 & 412 & 249 \\
\hline \multirow{2}{*}{$\begin{array}{l}\text { Chemiosmosis/ } \\
\text { Chemiosmotic }\end{array}$} & 2019 & 6 & 2 & 2 & 6 \\
\hline & 1968-2018 & 37 & 154 & 24 & 31 \\
\hline \multirow{2}{*}{$\begin{array}{l}\text { Proton } \\
\text { motive force / } \\
\text { Mitochondrial } \\
\text { proton pump }\end{array}$} & 2019 & 26 & 3 & 6 & 10 \\
\hline & 1968-2018 & 1038 & 267 & 69 & 48 \\
\hline \multirow{2}{*}{$\begin{array}{l}\text { Mitochondrial } \\
\text { membrane } \\
\text { potential }\end{array}$} & 2019 & 39 & 20 & 100 & 292 \\
\hline & 1968-2018 & 2770 & 1080 & 765 & 1190 \\
\hline \multirow{2}{*}{$\begin{array}{c}\text { Rotary ATP } \\
\text { synthase/ } \\
\text { synthesis }\end{array}$} & 2019 & 5 & 1 & 1 & 4 \\
\hline & 1968-2018 & 210 & 66 & 19 & 13 \\
\hline
\end{tabular}


Table 3. Number of hits obtained using Google Scholar in some prominent (ivy-league) journals of biochemistry.

\begin{tabular}{|c|c|c|c|c|c|c|c|}
\hline Term & Period & $\begin{array}{l}\text { Cell Press and } \\
\text { Cell } \\
\text { (Inception: 1974) }\end{array}$ & $\begin{array}{c}\text { Science } \\
\text { (Inception: } \\
\text { 1880) }\end{array}$ & $\begin{array}{c}\text { NPG \& } \\
\text { Nature } \\
\text { (Inception: } \\
1869)\end{array}$ & $\begin{array}{c}\text { PNAS } \\
\text { (Inception: } \\
\text { 1915) }\end{array}$ & $\begin{array}{c}\text { EMBO } \\
\text { (Inception: } \\
\text { 1982) }\end{array}$ & $\begin{array}{c}\text { FASEB } \\
\text { (Inception: } \\
\text { 1912) }\end{array}$ \\
\hline \multirow{2}{*}{$\begin{array}{l}\text { Electron } \\
\text { Transfer/ } \\
\text { Transport } \\
\text { Chain (ETC) }\end{array}$} & 2019 & 4 & 39 & 507 & $0^{*}$ & 19 & 74 \\
\hline & $1968-2018$ & 552 & 192 & 3205 & $3^{*}$ & 199 & 545 \\
\hline \multirow{2}{*}{$\begin{array}{l}\text { Chemiosmosis/ } \\
\text { Chemiosmotic }\end{array}$} & 2019 & 15 & 2 & 23 & 7 & 0 & 0 \\
\hline & 1968-2018 & 399 & 37 & 296 & 718 & 30 & 20 \\
\hline \multirow{2}{*}{$\begin{array}{l}\text { Proton } \\
\text { motive force / } \\
\text { Mitochondrial } \\
\text { proton pump }\end{array}$} & 2019 & 67 & 9 & 118 & 0 & 4 & 4 \\
\hline & 1968-2018 & 1120 & 97 & 738 & 4 & 125 & 125 \\
\hline \multirow{2}{*}{$\begin{array}{l}\text { Mitochondrial } \\
\text { membrane } \\
\text { potential }\end{array}$} & 2019 & 392 & 23 & 477 & 0 & 27 & 71 \\
\hline & 1968-2018 & 4320 & 77 & 3850 & 3 & 250 & 617 \\
\hline \multirow{2}{*}{$\begin{array}{l}\text { Rotary ATP } \\
\text { synthase/ } \\
\text { synthesis }\end{array}$} & 2019 & 13 & 22 & 28 & 0 & 6 & 2 \\
\hline & 1968-2018 & 291 & 116 & 209 & 1 & 215 & 9 \\
\hline
\end{tabular}

Table 4. Number of total hits obtained for the five keywords using Google Scholar.

\begin{tabular}{|c|c|c|c|c|c|c|}
\hline Keyword & $\begin{array}{c}\text { Electron Transfer/ } \\
\text { Transport Chain } \\
\text { (ETC) }\end{array}$ & $\begin{array}{c}\text { Chemiosmosis/ } \\
\text { Chemiosmotic }\end{array}$ & $\begin{array}{c}\text { Proton } \\
\text { motive force / } \\
\text { Mitochondrial } \\
\text { proton pump }\end{array}$ & $\begin{array}{c}\text { Mitochondrial } \\
\text { membrane } \\
\text { potential }\end{array}$ & $\begin{array}{c}\text { Rotary ATP } \\
\text { synthase/ } \\
\text { synthesis }\end{array}$ & \begin{tabular}{c} 
Grand Total \\
\hline $\mathbf{2 0 1 9}$
\end{tabular} \\
\hline $\mathbf{1 9 6 8 - 2 0 1 8}$ & 15296 & 698 & 3556 & 17520 & 1467 & 38537 \\
\hline Total & 54727 & 18438 & 53274 & 284152 & 17096 & 407687 \\
\hline
\end{tabular}

\section{THE SHEER MAGNITUDE OF COGNITIVE DISSONANCE IS DISILLUSIONING!}

As seen from the tables above, the usages of the controversial terms are overwhelmingly high in literature. If we conservatively assume that the number of papers are actually $\sim 100$ times what is returned by Google Scholar (considering the two examples of PNAS briefly discussed earlier), we arrive at millions of 'abuses' by tens of thousands of scientists in the last year alone! A diligent and responsible scientist is expected to keep a timely track of articles published in the field. Our first paper in Biomedical Reviews (13) should have been enough to elicit a critical response from at least one group across the world. But even after publishing several papers in the field, this has not happened! One of us has written to several read- ing researchers across the world but few have bothered to respond. From the open access web portals (where our papers/ preprints were published or are freely available), we can gauge that thousands of researchers would have come to know of our works by now. For example- (a) Biochemistry Insights (SAGE Group) website has Manoj's article (15) listed as the second 'most read' paper on its portal, with more than 500 downloads, (b) BiorXiv (CSH Lab) lists $>1000$ abstract/full text views, with $>250$ manuscript downloads for the paper that refutes the classical explanation for cyanide toxicity and advocates the murburn model for the acutely lethal effects of small amounts of cyanide. When considering that not one of the ones that voluntarily read our works cited them (whether in appreciative or critical vein), one must say that the global 
scientific temperament needs a lot desired! When considering that most of these scientists work at the expense of common taxpayers' toil, the extent of this cognitive dissonance is unacceptable at any levels, either in intellectual competitiveness or in moral integrity. For a better picture of what we discuss here, let us give you a brief input on the differences between the old and new models of mOxPhos.

\section{A CRASH COURSE IN CELLULAR BIOENERGETICS, FOR DIFFERENTIATING THE OLD AND NEW EXPLANATIONS}

The most striking difference between the KMB explanation and the murburn model is that; while the KMB model relies on protons as the protagonist (and considers oxygen's involvement only to make water at Complex IV), the new murburn model of $\mathrm{mOxPhos}$ proposes oxygen or diffusible reactive oxygen species (DROS) as the primary agent for explaining reaction outcomes. Also, while there is no direct chemical or physical connectivity of the oxidation of NADH with the reduction of water or ATP synthesis within the KMB model, the murburn model directly connects the various aspects of overall reaction outcomes. The KMB model is not energetically efficient, with only 2.5 ATP per NADH and 1.5 ATP per succinate/FADH $\mathrm{F}_{2}$, falling severely short of explaining the theoretically mandated and experimentally observed higher efficiencies. The murburn model is supported by structure function correlations, thermodynamics and chemical kinetics whereas the KMB model violates several chemico-physical aspects of mitochondrial biology and bioenergetics. Unlike the KMB model, the murburn scheme of mOxPhos does not rely on complex and sequential electron transfers, multi-molecular complexations, proton pumping, membrane potential, etc to explain ATP synthesis. While the KMB model is a complex and vitally deterministic scheme with very low appeal on probability or evolutionary considerations, the murburn model satisfies Ockham's razor and fares well on statistical and stochastic scales. For more elaborate comparisons and details of the two models, please refer to our earlier publications (13, 15-18). A study of these publications would inspire the doubtful to wonder how could mitochondria ever function, in the manner espoused by the KMB scheme (Fig. 1).

\section{OUR 'CRUSADE' AGAINST SOME EXTANT TERMINOLOGIES}

\section{Electron Transfer/Transport Chain (ETC) or respiratory} chain complexes: The KMB model vouches for the existence of an "electron transfer chain" of intrinsic redox proteins, which in turn, predictably move electrons along a sequential

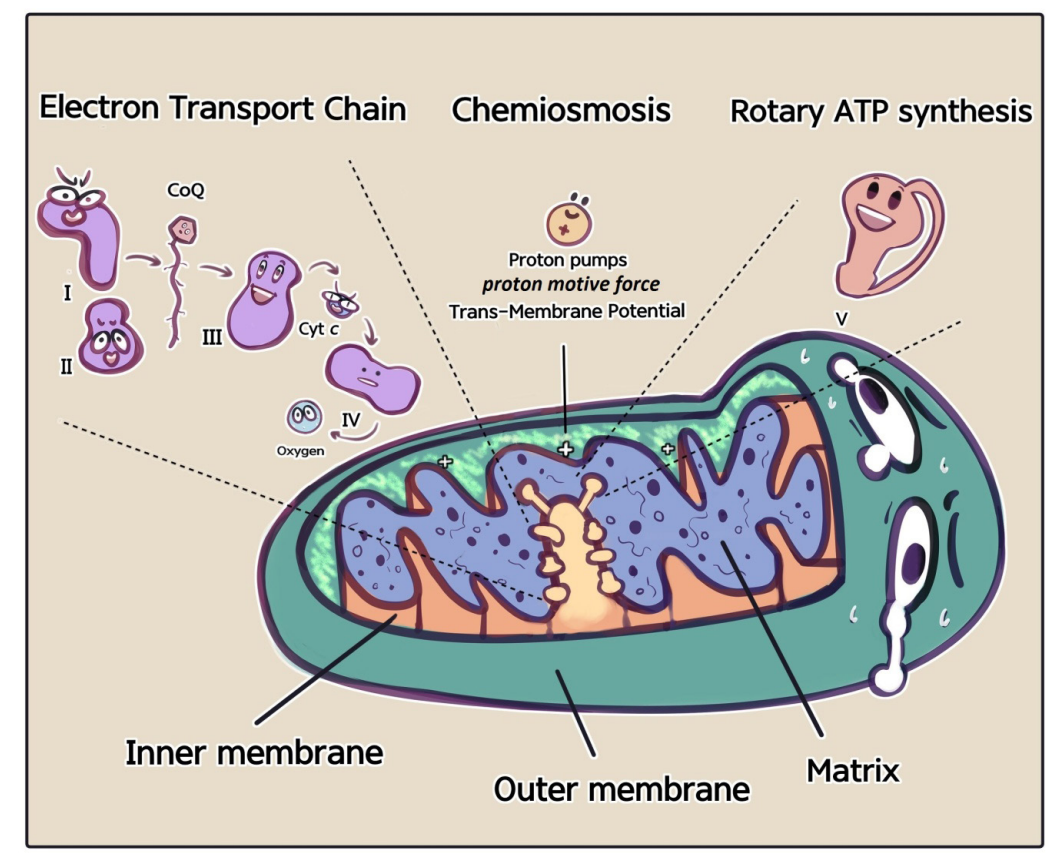

The mitochondrion wails: How could I work like this?

Figure 1. A cynic's view of the KMB model of mOxPhos, with the various elements, which seem to work in totally surreal, discordant and unproductive ways! 
route/path (18). As per this model, electrons are removed from $\mathrm{NADH}$ and $\mathrm{FADH}_{2}$ from complexes I and II, respectively, leading to the reduction of ubiquinone to ubiquinol. These reduced forms of ubiquinone are then sent from complex I and II to complex III, which transfers the electrons to complex IV via cytochrome $c$. Complex IV then reduces a molecule of bound oxygen to form water. This NADH/FADH ${ }_{2} \rightarrow \mathrm{O}_{2}$ relay of electrons is called Electron Transport Chain. A few random samples of such a concept forming crux of research projects are: In a study reported in the journal Mitochondrion, the authors studied the effect of 6-hydroxydopamine on the "functioning of the mitochondrial electron transfer chain complexes" (19). In the book "Advances in Microbial Physiology", the authors of the chapter entitled "The plethora of membrane respiratory chains in the phyla of life" discuss the arrangement and mechanism of eukaryotic (animal, plant, fungi, protozoa) as well as prokaryotic (bacteria) "electron transfer chains" (20). The same terminology has been used in several other papers $(21,22)$.

\section{Why ETC must go!}

The statement "mitochondrial respiratory chain complexes or electron transport chain" is potentially misleading because mitochondrial electron transfer is not organized in the form of ordered and sequential reactions, but is a disordered and probabilistic process. The selectivity and rates of the reactions, and the overall statistical outcomes thereof are governed by a network of interactions mediated by DROS (13-16). The formation of DROS can occur at multiple sites in different protein complexes within the membrane and the path of electron transfer is not necessarily arranged in the order of redox potential of the four complexes (I-IV). We see the 'relatively slow' effect that Complex I gets reduced before Complex III, and Complex IV gets reduced after Complex III because Complexes III and IV are 'turbo' agents, which recycle the electrons lost to CoQ, cytochrome $c$ and peroxide. Therefore, as there is neither a 'chain' nor a 'transport of electrons' to make water, it is also semantically erroneous to use the word "electron transport chain" or "respiratory chain" when referring to the mitochondrial reaction system. All of the mitochondrial membrane protein complexes I-IV generate DROS and make ATP. So, they are pseudo ATP synthases or murzymes, per the new perception.

2. Mitochondrial proton pumps: Several researchers in the field of bioenergetics call mitochondrial Complexes I, III \& IV as mitochondrial proton pumps (23). This is because the KMB model proposes that a serial movement of electrons through various redox centers of the membrane complex proteins enables a translocation of protons across the inner mitochondrial membrane via the proteins' trans-membrane domains, from the matrix to the inter-membrane space.

\section{Why mitochondria cannot have proton pumps?}

A simple calculation shows that at physiological setups, a mitochondrion has $<10^{1}$ protons but $>10^{5}$ respiratory membrane protein complexes. Surely, the humongous numbers of protein (super)complexes present are not to pump protons, as there are little protons to pump. Even otherwise, pumping is a phenomenon invoked to explain the bulk and forceful projection of fluids, not small and practically non-available entities like protons! Therefore, the terminology of mitochondrial proton pumps must be discarded!

3. Mitochondrial membrane potential: The removal of protons from matrix by purported proton pumps is supposed to lead to significant excess negative charge within the matrix and a surplus positive charge within the inter-membrane space. This is supposed to lead to a trans-membrane potential (TMP), which went on to be corrupted, to become the mitochondrial membrane potential prevalent in literature today.

\section{Why do we have a problem with 'mitochondrial membrane potential'?}

A potential difference is measured between two points (as Mitchell solicited, across the inner mitochondrial membrane, between two microscopic phases of matrix and inter-membrane space or IMS). The word trans-membrane potential is much more accurate, but many authors use words such as "mitochondrial membrane potential" instead. Therefore, the term "membrane potential" carries the connotation that the membrane itself contains or retains some kind of electrochemical discretionary potential of its own. Many authors carelessly use this word and some salient examples from articles published in 2019 (21-23). Contrary to the KMB model, we have clearly argued through quantitative analysis that a significant TMP accompanied by an adequate charge cannot be formed with a miniscule number of protons $(16,18)$. Also, TMP is not the driving force but only the result of a net negative charge generated by reactive oxygen species accumulating in steady state within the mitochondrial matrix. Of all the faulty terms in mOxPhos, this is the most important one because it is the most highly used and abused one. A trans-membrane or electrical potential cannot drive phosphorylation (18), as the redox 
process of ATP-synthesis occurs in the inner mitochondrial membrane-matrix interface. (Also, in thermodynamic terms, this is like double cashing of the same cheque from an account with inadequate funds!) Quite simply, TMP is not the driving horse, but an accompanying or driven cart in mOxPhos!! Also, the TMP in the KMB model should have been demonstrated and measured between the IMS and matrix, not between cytoplasm and matrix. This important conceptual issue was pointed out (15) but not recognized by the scientists. Therefore, to stress on the real chemistry within matrix, and to avoid the conceptual errors of "single point potential attributions", the term "mitochondrial potential" should be shown the door.

4. Chemiosmosis: This terminology was invented by Peter Mitchell. The pumping or activated outward movement of protons across the inner mitochondrial membrane is supposed to lead to a crowding of extra protons within the IMS and also a sparse distribution of protons within matrix. That is, protons are at a higher packing density in the IMS compared to matrix, in the steady state. This scenario leads to a spontaneous return of the excess protons from IMS to matrix, and this supposed "colligative" phenomenon was called chemiosmosis. Torday argues in his review article that evolution was made possible by chemiosmosis (24). He says that from the very beginning of life, both in the ontogenetic as well as phylogenetic sense and based on cellular-molecular principles, the mechanism of perpetuation of biology in the face of environmental stress can be elucidated. Three important things - negatropy, chemiosmosis and homeostasis to him are responsible for providing the initial conditions that aided in bringing about evolution as well as homeostasis. An article published in the journal PNAS by Schoelmerich et al. state that 'chemiosmosis' and 'substrate level phosphorylation' are the two mechanisms employed in the formation of ATP (25).

\section{Why is chemiosmosis a mirage that serves no purpose?}

Osmosis is the free movement of solvent molecules, from a phase of lower solute concentration, across a semipermeable membrane (which does not freely permit the solute movement), to a phase of higher solute concentration (dissolved with the same common solvent). Diffusion is the movement of solute particles in a medium, leading to homogenetic distribution of the same, in the presence or absence of a freely permissible membrane. Chemiosmosis creates a mirage by a mix and match of the two concepts above and there is no real instance of such a chemiosmotic process anywhere else in the real world, to the best of our beliefs. Moreover, this idea also defies fundamental thermodynamics concepts (15). Our group perceives that the miraculous gambit of chemiosmosis cannot exist and therefore, cannot account for anything, let alone an important process like origin and evolution of life! Therefore, a surreal chemiosmosis has no relevance in the real life pursuits of scientists.

5. Proton motive force (pmf): This is yet another Mitchellian invention derived from the more commonly and accepted concept of electromotive force. When the crowded protons from within IMS spontaneously re-enter the matrix, they are supposed to have "power/energy" to drive ATP synthesis. The cyclic movement of protons of energized and energydissipated protons in such a manner was recently also given the depiction of "lines of proton motive force", quite similar to the magnetic lines of force drawn in a bipolar magnet (26). Schlame opined that the "proton motive force" is largely confined to the crista membrane and not to other areas on the inner membrane. He argued that the "underlying mechanism" for the confinement of "pmf" to the crista membrane alone could be owing to "proton loop between the respiratory chain and ATP synthase" to facilitate keeping the "proton motive force away from the inner boundary membrane due to specific localization of the proton pump". Terminologies such as "trans-membrane proton gradient", "proton motive force", "chemiosmotic potential", "electrochemical potential" all mean the same thing - and refer to the Mitchellian proposal of difference in $\mathrm{H}^{+}$concentration/packing in matrix vis a vis IMS, in the steady state. With respect to antimicrobial chemotherapy (using antibiotics), the words "membrane potential" and "proton motive force" are often encountered. Using in vivo 3-dimensional lung epithelial cell models, Crabbé et al. (27) endeavoured to replicate conditions which are conducive to host-pathogen settings typically encountered in physiology. After infection of the cells by treating them with Pseudomonas aeruginosa, the authors studied cross-talk between host and bacterial metabolic pathways which occur during antibiotic chemotherapy. Their assays indicated that the 3-dimensional cell conditioned medium "stimulated the proton motive force (pmf)" and caused bacterial intracellular $\mathrm{pH}$ to increase. Several leading researchers in the field of microbiology deem that "membrane potential" alterations and "stimulation of proton motive force" increase the uptake of antibiotics. A US patent filed in 2019 by Dr. Collins is entitled "proton motive force stimulation to potentiate aminoglycoside antibiotics against persistent bacteria" (28). Similar studies were conducted and 
the role of "pmf" and in enhancing the efficacy of antibiotics/ antimicrobial preparations was explored (29-31).

\section{Why is proton motive force a bad idea?}

The idea of a proton motive force stems from the lacuna of "connectivity" of the earlier perceived ETC and the mirage of chemiosmosis with the actual process of ATP synthesis. While electrons can conduct through ionic medium and metallic conductors, protons movement or hopping across phases are no way perceivable as a driving force. All of such misperceptions arose from the failure to see the mitochondrial medium as an essentially aprotic environment in which water or quinol or peroxide formation requires cytoplasmic protons to form the $\mathrm{O}-\mathrm{H}$ bonds. The O-H bond formation is the chemically/thermodynamic pull or driving force of ATP synthesis in mOxPhos. So, pmf was yet another mirage in mOxPhos bioenergetics, and it too must go.

6. Rotary ATP synthesis/synthase: This terminology was invented by Boyer and refers to rotation of several components within the $\mathrm{F}_{0} \mathrm{~F}_{1}$ ATPsynthase and a cyclic generation of ATP by proton motive force mediated fusion of ADP and Pi. Several sophisticated evidence have been presented to support this highly speculative concept.

\section{Why is a rotary ATP synthase activity physiologically irrelevant and improbable?}

Complex V is unlikely to be an ATPsynthase, as it has higher affinity for ATP (than ADP). Our earlier works have provided ample structure function correlations (and interpretation of earlier experiments by other researchers) to support the murburn proposal that the activities of complexes I to IV synthesize ATP, whereas Complex V serves to aid ATP synthesis in a roundabout way by recruiting protons at the matrix-membrane interface. Other workers have shown that both prokaryotic and eukaryotic systems can survive without a functional Complex V (35-36). This aspect conclusively discredits Complex V's role as the physiological ATP synthase. We can extend our imagination to consider a rotary ATPase activity at the most (a hydrolysis of ATP in the matrix recruiting an inlet of protons via a rotary function), but that itself would necessitate a letting go of all cynic faculties. A rotary ATPsynthase activity (where $\sim 3$ protons' inward movement enables the synthesis of one molecule of ATP) does not justify molecular stoichiometries or quantitative necessities dictated by energetics. And to the best of our knowledge, we don't see such a sophisticated outcome (37) being sponsored from the simple structure that the pio- neers Walker and Boyer themselves have elucidated! So, rotary ATP synthase is another term that should be discontinued.

\section{CONCLUSION: WHY SO MUCH ADO ABOUT SEMANTICS IN SCIENCE?}

Any living being needs a powering logic to commission the works of life. Oxidative phosphorylation or cellular respiration forms the pivotal logic of this powering mechanism. Photophosphorylation is another routine, which has several commonalities with the OxPhos scheme, and therefore, our works are relevant in plants' oxygenic photosynthesis too (38). So, what we discussed above directly impacts the prospects of understanding 'life' as we know, on the planet Earth. In a pioneering article in Biomedical Reviews (13), one of us had conclusively argued against the extant paradigm of cellular respiration as taught in schools, colleges and universities across the globe. In lieu, an experimentally supported and thermodynamically/kinetically viable/tangible murburn reaction mechanism was floated for the MOST important metabolic routine of life. The ubiquitous biochemical logic of murburn theory and its ramifications in biology and medicine is apparent, from the electron/moiety transfer chemistry insights gained from HPO, CYP and pertinent redox enzymology $(32,39)$. Murburn concept offers a fresh and totally radical paradigm for the perception and interpretation of several fundamental biochemical and physiological concepts (39). Contrary to the commonly prevailing perception that DROS (like superoxide and hydroxyl radicals) are bad, our works show them as the quintessential agents of electron/moiety transfers, on which life is built. Such a profound concept that reorients biochemistry and medicine research perspectives (40) needs to be acknowledged by the research community for advancement of science and for human benefit, in general. This is not a trivial matter, in any criteria of assessment, and our works should have attracted the attention/appreciation/criticism of scientists across the globe. Whenever one of us presented the works/ideas at talks, or even when the works were sent for peer review, scientists would be dismissive merely because we challenged Nobel-recognized ideas. Nobel recognitions, though deserving highest veneration and carried out with utmost deliberations, are quite like all human endeavors- prone to error in judgment! Therefore, Nobel recognitions are not sanctions of immunity and impunity. In Science, there have been at least three instances where the respective committees left a lot desired- (i) Johannes Fibiger (1926) was awarded a Nobel in medicine for insisting that rats ingesting worm larvae via eating cockroaches developed cancer, and this proved to be untrue. (ii) Antonio 
Egas Moniz (1949) was again awarded a Nobel in medicine for lobotomy, sectioning off a part of brain, to treat some psychiatric disorders. This was soon proven to be an inhuman practice. (iii) Paul Mueller (1948) was awarded a Nobel in Chemistry for DDT (which he didn't invent, but applied), a pesticide. Surely, the chemical did kill bugging insects but was banned subsequently owing to very harmful environmental effects. The above instances are not cited to look down at the Nobel recognition (how could we, when one of us hopes to secure a few of them soon!), but to stress on the importance of the agenda at hand. There are a multitude of redox diseases and nutrition/ aging-related issues, therapeutic approaches and our quest for understanding the deep-rooted origins and mechanisms of life that need to be reconsidered and overhauled in the light of the new findings that we have unleashed. The fact that some erroneous ideas were awarded with a few Nobel recognitions should not stop real scientists from questioning inaccurate explanations and seeking better ones. For, it is our lives and the education of generations of mankind that is at stake here! It is important to understand the processes involved in energy metabolism clearly and thoroughly. If we need to translate concepts from bench to bedside, we cannot afford to make erroneous judgments which arise from faulty perceptions. The words and theories to which one subscribes to are therefore important in determining how ideas are pursued and the resulting potential usefulness thereof. To reiterate, words and terminologies are the very tools with which we express and comprehend ideas. If unchecked and uncontested, continuation and further propagation of the same erroneous ideas would result, and useful experimental data could potentially be misinterpreted by erroneous perspectives. Let 2020 be the time for foresight and ushering in changes, so that at the end of the year, we can say in hindsight that our vision was 20-20! Let not vested interests make us myopic, and let us not get clouded by cataracts!

\section{DISCLAIMERS AND ACKNOWLEDGMENTS}

The authors have no conflict of interests to disclose. KMM credits Adhiatma Therat for the cartoon/cover-page image on mitochondria.

\section{REFERENCES}

1. Slater EC. Mechanism of phosphorylation in the respiratory chain. Nature 1953; 172: 975-978. DOI:10.1038/172975a0

2. Mitchell P. Coupling of phosphorylation to electron and hydrogen transfer by a chemi-osmotic type of mechanism. Nature 1961; 191: 144-148. DOI:10.1038/191144a0

3. Mitchell P. Chemiosmotic coupling in oxidative and pho- tosynthetic phosphorylation. Biol Rev 1966; 41: 445-501. DOI: 10.1016/j.bbabio.2011.09.018.

4. Ling GN. Oxidative phosphorylation and mitochondrial physiology: a critical review of chemiosmotic theory, and reinterpretation by the association-induction hypothesis. Physiol Chem Phys 1981; 13: 29-96.

5. Slater E. An evaluation of the Mitchell hypothesis of chemiosmotic coupling in oxidative and photosynthetic phosphorylation. Eur J Biochem 1967; 1: 317-326. DOI:10.1007/978-3-662-25813-2_43.

6. Slater E. The mechanism of the conservation of energy of biological oxidations. Eur J Biochem 1987; 166: 489-504. DOI:10.1111/j.1432-1033.1987.tb13542.x

7. Wainio W. An assessment of the chemiosmotic hypothesis of mitochondrial energy transduction. In: Int Rev Cytol 1985; 96: 29-50. DOI:10.1016/S0074-7696(08)60593-8.

8. Boyer PD. Phosphohistidine. Science 1963; 141: 11471153. DOI:10.1126/science.141.3586.1147.

9. Boyer PD. Molecular motors: What makes ATP synthase spin? Nature 1999; 402: 247-249. DOI:10.1038/46193.

10. Abrahams JP, Leslie AG, Lutter R, Walker JE. Structure at 2.8 Å resolution of $\mathrm{F}_{1}$-ATPase from bovine heart mitochondria. Nature 1994; 370: 621-628. DOI:10.1038/370621a0.

11. Stock D, Leslie AG, Walker JE. Molecular architecture of the rotary motor in ATP synthase. Science 1999; 286: 1700-1705. DOI: 10.1126/science.286.5445.1700.

12. Walker JE, Saraste M, Runswick MJ, Gay NJ. Distantly related sequences in the alphaand betasubunits of ATP synthase, myosin, kinases and other ATP requiring enzymes and a common nucleotide binding fold. EMBO J 1982; 1: 945-951. DOI:10.1002/j.1460-2075.1982.tb01276.x

13. Manoj KM. Debunking chemiosmosis and proposing murburn concept as the operative principle for cellular respiration. Biomed Rev 2017; 28: 31-48. DOI:10.14748/ bmr.v28.4450.

14. Manoj KM, Gideon DA, Jacob VD. Murburn scheme for mitochondrial thermogenesis. Biomed Rev 2018; 29: 7382. DOI:10.14748/bmr.v29.5852.

15. Manoj KM. Aerobic respiration: Criticism of the protoncentric explanation involving rotary adenosine triphosphate synthesis, chemiosmosis principle, proton pumps and electron transport chain. Biochem Insights 2018; 11: 1178626418818442. DOI:10.1177/1178626418818442.

16. Manoj KM, Parashar A, Jacob VD, Ramasamy S. Aerobic respiration: proof of concept for the oxygen-centric murburn perspective. J Biomol Struct Dyn 2019; 37: 45424556. DOI:10.1080/07391102.2018.1552896.

17. Manoj KM, Ramasamy S, Parashar A, Soman V, Pakshirajan K. Murburn concept explains the acutely lethal effect of cyanide. bioRxiv 2019; 555888. DOI:10.1101/555888. 
18. Manoj KM, Soman V, Jacob VD, Parashar A, Gideon DA, Kumar M, et al. Chemiosmotic and murburn explanations for aerobic respiration: Predictive capabilities, structurefunction correlations and chemico-physical logic. Arch Biochem Biophys 2019; 676: 108128. DOI:10.1016/j. abb.2019.108128.

19. Kuter KZ, Olech Ł, Dencher NA. Increased energetic demand supported by mitochondrial electron transfer chain and astrocyte assistance is essential to maintain the compensatory ability of the dopaminergic neurons in an animal model of early Parkinson's disease. Mitochondrion 2019; 47: 227-237. DOI:10.1016/j.mito.2018.12.002.

20. Refojo PN, Sena FV, Calisto F, Sousa FM, Pereira MM. The plethora of membrane respiratory chains in the phyla of life. Adv Microb Physiol 2019; 74: 331-414. DOI:10.1016/bs.ampbs.2019.03.002.

21. Ramírez-Camacho I, Flores-Herrera O, Zazueta C. The relevance of the supramolecular arrangements of the respiratory chain complexes in human diseases and aging. Mitochondrion 2019; 47: 266-272. DOI:10.1016/j. mito.2019.01.001.

22. Wang Y, Palmfeldt J, Gregersen N, Makhov AM, Conway JF, Wang $M$, et al. Mitochondrial fatty acid oxidation and the electron transport chain comprise a multifunctional mitochondrial protein complex. J Biol Chem 2019; 294: 12380-12391. DOI:10.1074/jbcRA119.008680.

23. Sazanov LA. A giant molecular proton pump: structure and mechanism of respiratory complex I. Nat Rev Mol Cell Biol 2015; 16: 375-388. DOI:10.1038/nrm3997.

24. Franke JM, Raliski BK, Boggess SC, Natesan DV, Koretsky ET, Zhang P, et al. BODIPY Fluorophores for membrane potential imaging. J Am Chem Soc 2019; 141: 12824-12831. DOI:10.1021/jacs.9b05912.

25. Grenier V, Daws BR, Liu P, Miller EW. Spying on neuronal membrane potential with genetically targetable voltage indicators. J Am Chem Soc 2019; 141: 1349-1358. DOI:10.1021/jacs.8b11997.

26. Mills E, O’Neill LA. Not all mitochondrial cristae are the same: Hetero-potential in the inner mitochondrial membrane. Immunometabolism 2020; 2: e200003. DOI:10.20900/immunometab20200003.

27. Torday JS. The Singularity of nature. Prog Biophys Mol Bio 2019; 142: 23-31. DOI: 10.1016/j.pbiomolbio.2018.07.013.

28. Schoelmerich MC, Müller V. Energy conservation by a hydrogenase-dependent chemiosmotic mechanism in an ancient metabolic pathway. Proc Natl Acad Sci USA 2019; 116: 6329-6334. DOI:10.1073/pnas.1818580116.

29. Schlame M. Mitochondrial cristae as insulated transform- ers of metabolic energy. EMBO J 2019; 38: e103472. DOI:10.15252/embj.2019103472.

30. Crabbé A, Ostyn L, Staelens S, Rigauts C, Risseeuw M, Dhaenens $\mathrm{M}$, et al. Host metabolites stimulate the bacterial proton motive force to enhance the activity of aminoglycoside antibiotics. PLoS Pathog 2019; 15: e1007697. DOI:10.1371/journal.ppat.1007697.

31. Collins JJ, Allison KR, Brynildsen MP. Proton-motive force stimulation to potentiate aminoglycoside antibiotics against persistent bacteria. 2019 US20170119805A1 (US Patent).

32. Magnowska Z, Jana B, Brochmann RP, Hesketh A, Lametsch R, De Gobba, et al. Carprofen-induced depletion of proton motive force reverses TetK-mediated doxycycline resistance in methicillin-resistant Staphylococcus pseudintermedius. Sci Rep 2019; 9: 1-14. DOI:10.1038/ s41598-019-54091-4.

33. Wang Y, Qin Y, Zhang Y, Wu R, Li P. Antibacterial mechanism of plantaricin LPL-1, a novel class IIa bacteriocin against Listeria monocytogenes. Food control 2009; 97: 87-93. DOI:10.1016/j.foodcont.2018.10.025.

34. Wu SC, Han F, Song MR, Chen S, Li Q, Zhang Q, et al. Natural flavones from Morus alba against methicillinresistant Staphylococcus aureus via targeting the proton motive force and membrane permeability. J Agric Food Chem 2019; 67: 10222-10234. DOI:10.1021/acs. jafc.9b01795.

35. Klionsky DJ, Brusilow WSA, Simoni RD. In vivo evidence for the role of the epsilon subunit as an inhibitor of the proton-translocating ATPase of Escherichia coli. $J$ Bacteriol 1984; 160: 1055-1060.

36. Sturm A, Mollard V, Cozijnsen A, Goodman CD, McFadden GI. Mitochondrial ATP synthase is dispensable in blood-stage Plasmodium berghei rodent malaria but essential in the mosquito phase. Proc Nat Acad Sci USA 2015; 112: 10216-10223. DOI: 10.1073/pnas.1423959112.

37. Manoj KM. Murburn concept: a paradigm shift in cellular metabolism and physiology. Biomol Concepts 2020 (In Press).

38. Manoj KM. Oxygenic photosynthesis: Critiquing the standing explanations and proposing explorative solutions based in murburn concept. OSF Preprints 2019. DOI: 10.31219/osf.io/3mzfp.

39. Manoj KM. The ubiquitous biochemical logic of murburn concept. Biomed Rev 2018; 29, 89-97. DOI:10.14748/ bmr.v29.5854.

40. Jacob VD, Manoj KM. Are adipocytes and ROS villains, or are they protagonists in the drama of life? The murburn perspective. Adipobiology 2019; 10:1-10. 